Article

\title{
Aesthetic Experience as an Essential Factor to Trigger Positive Environmental Consciousness
}

\author{
Po-Ching Wang ${ }^{1}$ and Chi-Ying Yu ${ }^{2, *}$ \\ 1 Department of Landscape Architecture, National Chiayi University, 300 Syuefu Road, \\ Chiayi City 60004, Taiwan; gaiascape@hotmail.com \\ 2 Department of Arts and Design, National Tsing Hua University, 521 Nan-Da Road, \\ Hsinchu City 30014, Taiwan \\ * Correspondence: chiying.yu@mx.nthu.edu.tw; Tel.: +886-3-571-5131 (ext. 72937)
}

Received: 14 February 2018; Accepted: 30 March 2018; Published: 6 April 2018

\begin{abstract}
The current environmental attitude models are primarily composed of environmental knowledge, value, and intention. However, environmental aestheticians have maintained that aesthetic experience triggered by nature is the cornerstone of promoting environmental ethics. To verify this belief, this study proposes a new framework, which integrates the rational and emotional approaches, to describe the environmental attitudes of the public. Questionnaires are used to collect data from college students in Taiwan, and a total of 275 valid responses are received. The collected data are analyzed using structural equation modeling. The results support the proposed hypotheses. In addition to reconfirming the importance of environmental knowledge in the traditional models, this study confirms that aesthetic experience is also a determining dimension. The findings show that rational cognition and aesthetic perception complement and interact with each other and can strengthen environmental ethics, thereby enhancing the intention of pro-environmental behavior. The results of this study can serve as a reference for environmental protection or environmental education practice.
\end{abstract}

Keywords: aesthetic experience; environmental aesthetics; environmental ethics; behavioral intention

\section{Introduction}

Many of the traditional environmental attitude models in general comprise environmental knowledge, environmental value, environmental intention, and environmental behavior. According to these widely-known and applied models, rational environmental cognition facilitates identification with environmental value and, thus, produces a mentality and behaviors that are consistent with environmental ethics (cf. [1-4]). However, according to Otto and Pensini's [5] study, the acquirement of environmental knowledge is less effective in promoting appropriate ecological behavior than the establishment of an intrinsic sense of connectedness to nature. The more individuals feel attached to nature, the more they display environmentally-friendly conduct. This discovery indicates that an internal driving force is more helpful in awakening environmental consciousness. The history of environmental protection also seems to demonstrate that our concern for the environment stemmed from the love of natural beauty rather than for cognitive reasons. Hargrove argued that the history of environmental conservation originated in aesthetics, and that environmental value was first manifested in the highlighting of aesthetic qualities of natural objects by naturalists and artists [6]. Similarly, Callicott [7] (p. 158) mentioned that "Historically ... many more of our conservation and preservation decisions have been motivated by beauty than by duty". Therefore, the aesthetic sensibility of an individual toward the environment may be another crucial factor that stimulates environmental ethics. 
In the wave of environmental aesthetics that emerged since the second half of the 20th century, aestheticians maintained that aesthetic experiences inspired by nature are a cornerstone of promoting environmental ethics [8-13]. Eco-friendly facilities designed in accordance to people's aesthetic preferences are proven to be more appreciated and supported by the public. Looks seem to matter in the campaign of environmental protection [14,15]. The scope of aesthetics, however, is not merely limited to the appearance of things. It is argued that the aesthetic experience gained from nature is not only an experience of beauty or an examination of aesthetic properties. Carroll [16] stressed that the appreciation of nature is derived from emotion and imagination; for example, fallen, decaying leaves are carpet-like in their softness, giving people the sense that they have returned home. Rolston, on the other hand, advocated an expanded aesthetic view based on environmental knowledge. Scientific cognition enables humans to recognize certain aesthetic aspects of nature, especially those aspects that have thus far defied human perception [10].

As discussed above, in the existing environmental attitude models, environmental cognition has been repeatedly confirmed to play a crucial role in promoting environmental ethics and intention (e.g., [3]); this aspect has resonated with the science-based environmental aesthetics (e.g., [10]). However, the function of aesthetic experiences based on emotion, feeling, and even imagination in the process of shaping environmental attitude has yet to been considered and verified. If aesthetic experiences can indeed trigger a sense of obligation, the sensitivity of an individual to aesthetics may become a key factor in the environmental protection movement. Therefore, this study intends to investigate the possible role aesthetic experience plays in an effective environmental attitude model. The relationship between aesthetics and rational cognition is expected to be clarified. A conceptual research framework is proposed, as shown in Figure 1, to suggest that the emotional and rational judgments of individuals will affect their own behavioral intentions.
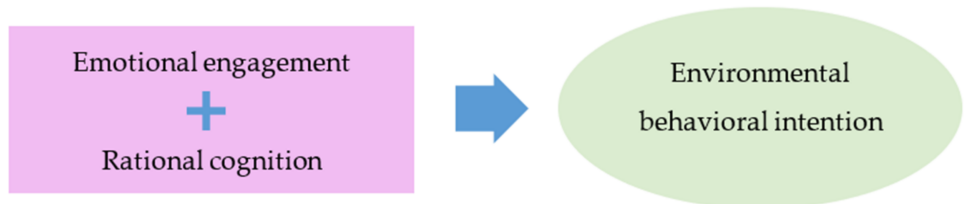

Figure 1. Conceptual research framework.

\section{Environmental Attitude, Behavioral Intention, and Behavior in Traditional Social Science}

In environmental protection research, discussions of environmental attitude have continually received considerable attention. Many scholars have also proposed different theoretical models to predict the behavioral intentions and behavior of people toward environmental protection. In previous studies, most scholars have adopted a relatively simple and linear causality to explain the concept of attitude. For example, in social science, Allport ([1], as cited in [17]) proposed a theory comprising the three dimensions of knowledge, attitude, and behavior. This theory was subsequently applied to many predictive models of pro-environmental behavior developed in the 1970s. These models suggested that, by providing environmental education, individuals could acquire environmental knowledge on a certain topic, thereby generating specific attitude orientations among them and facilitating their engagement in corresponding environmental behavior. To date, many environmental nongovernmental organizations (NGOs) and related groups continue to uphold this core belief [3]. Schwartz [18] originally employed the three concepts of knowledge, attitude, and behavior to propose the knowledge-attitude-practice (KAP) linear model in the field of nutrition. The model describes that, after acquiring nutrition-related knowledge, individuals change their views of products and proceed to make different decisions. This concept of KAP was further employed to predict the environmental behavior of individuals [4]. Following the rapid expansion of research on environmental behavior, some scholars believed that attitude itself includes three elements, namely cognition, affect, and behavior, and they proposed relevant theoretical models based on these elements. For example, 
the affect-behavior-cognition $(\mathrm{ABC})$ model of attitudes suggests that the feelings of individuals generated by a stimulus pertain to the affective aspect, thoughts generated by a stimulus pertain to the cognitive aspect, and the generated intentions or behaviors pertain to the behavioral aspect [19]. Many subsequent empirical models, such as the tripartite model of attitude proposed by Breckler [20], verified that the three elements originally attributed to attitude could be viewed as three independent components. In the discussion of environmental topics, Grob [21] also disassembled environmental attitude into different dimensions and discussed the causal relationships between them.

Previous studies indicated that acquiring environmental knowledge does not necessarily generate positive environmental attitudes and behavior (e.g., [4]). Some researchers argued that knowledge and beliefs can only influence behavior by enhancing behavioral intention, and they divided factors affecting behavioral intention into two types: the feeling of engaging in specific behaviors, or attitude towards behavior, and behavior influenced by relevant parties or groups, or subjective norm [22]. This was called the theory of reasoned action (TRA). Ajzen [23] expanded the concept of TRA by adding the dimension of perceived behavioral control to explain the influence of surrounding resources and restrictions on individual behavioral intention and then proposed the theory of planned behavior (TPB). Hines, Hungerford, and Tomera [24] referenced the concept of TPB and proposed the model of responsible environmental behavior (MREB), in which situational factors are used to enhance the prediction accuracy of pro-environmental behavior. Stern [25] referenced the norm-activation model (NAM) described by Schwartz [26] and proposed the value-belief-orm (VBN) theory, which uses a series of causal chains to explain the relationship between individual values and environmental protection behavior.

Most recent studies have been based on the aforementioned theoretical models or have combined theories from other disciplines to discuss different environmental topics, for example, examining consumer perceptions of renewable energy [27], environmental managers' attitude toward environmental norms aiming at pollution reduction [28], or focusing on the choice intention of travelers for green hotels [29]. For instance, Oreg and Katz-Gerro [30] combined the theories of TPB and VBN and employed 27 countries as a sample to study cross-cultural pro-environmental behavior and examine the influence of different values and social factors on environmental behavioral intention. Kollmuss and Agyeman [3] reviewed relevant theories and developed a new pro-environmental behavior model, in which internal factors (e.g., individual characteristics or values) and external factors (e.g., social policies or economic conditions) were assumed to influence each other and directly or indirectly influence the pro-environmental behavior of individuals.

\section{Aesthetic Experience and Environmental Protection}

\subsection{Nature as a Source of Aesthetic Experience}

Nature has long been a topic in aesthetic studies. In the 18th century, Alexander Baumgarten, the German philosopher, coined the word aesthetica; he defined it as the science of sensual perception. Objects for aesthetic appreciation are not limited to works of art; rather, aesthetic experiences triggered by nature cause more contemplation in philosophers [31]. Kant considered nature to be a more ideal object of appreciation than art and believed that it can create more mental activities in viewers [32]. Burke and Kant [32,33] defined two typical aesthetic dimensions based on diverse natural phenomena: the beautiful and the sublime. The Beautiful refers to a landscape that has undergone design and domestication, while the sublime is a natural environment that is wild and uninhibited. Carlson [34] also identified the third typical dimension of aesthetics—the picturesque. This is a form that connects nature and art, treating nature as an object for aesthetic appreciation, as if they are framed landscapes. Consequently, this has formed the tradition of landscape painting in the art world. However, since the 19th century, nature aesthetics has been reduced to a vassal of art aesthetics [35], and art has become the primary focus of aestheticians. Hegel believed that the beauty of art is superior to that of nature; analytic aesthetics became the mainstream, and philosophy of art became a synonym for 
aesthetics. Until the mid-20th century, few researchers discussed nature aesthetics, with only a few exceptions. For example, Dewey attempted to reintroduce nature and everyday life into studies of esthetic experience, which slightly encouraged the focus on nature in discussions of aesthetics [34]. The monopoly of art in the field of aesthetics began to mitigate in the second half of the 20th century. In 1966, Ronald W. Hepburn published a paper titled "Contemporary Aesthetics and the Neglect of Natural Beauty," which indicated the long-term bias in the aesthetic field that favored art over nature. As environmental issues have gradually drawn the attention of the public, environmental aesthetics has become an emerging field [34].

Environmental aestheticians have revealed the richness of nature as an aesthetic object and have indicated various distinctive modes of appreciation. Some regard nature and art as highly similar entities. For example, Arnold Berleant suggested that art and nature should be approached using similar aesthetic standards, and, as per Berleant, art and nature should be evaluated from the perspective of formalism. In other words, much like one would with a work of art, it is necessary to apply objective knowledge of aesthetic appreciation in order to interpret the beauty of nature [34].

Other environmental aestheticians, such as Hepburn [36], believed that the full-body immersion of viewer marks a substantial difference between the experiences of appreciating nature and appreciating art. Unlike the detached mode of appreciation in viewing art, in natural settings, people are absorbed extensively and therefore more easily evoke metaphysical imagination [15,36-40]. In fact, an innate connectedness to nature is the state of mind that one can develop when interacting with nature [41,42]. Whether it is approached through cognitive [41], experiential [42], or belief-oriented [43] paths, the emotional attachment between human beings and the environment is predictor of appropriate ecological behavior [5].

\subsection{Relationship between Environmental Aesthetics and Environmental Ethics}

The aesthetic experience provided by nature is considered an effective stimulus to evoke environmental ethics, thereby encouraging individuals to engage in environmental protection [8-13]. Aldo Leopold, a well-known conservationist and nature writer, linked land ethics and land aesthetics and made the appeal that the land is where human culture was born, and that culture is "the aesthetic harvest" derived from the land [9] (p. viii). Leopold believed that the capacity to appreciate nature's beauty drives one to protect the environment. In other words, an aesthetic experience of nature is bound to be accompanied by environmental consciousness. Therefore, it is crucial to cultivate aesthetic sensitivity to protect the environment [8]. As per Brady [44], Leopold's argument threw light on the compatibility of beauty and moral goodness. Then, as per this view, it is easier to arouse the need to protect the environment through an appeal to aesthetics; in addition, environmental protection is regarded as a virtue that should be cultivated.

The intuitive perception of nature and the subconscious immersion within its systems may influence a person's attitudes toward environmental issues. Otto and Pensini [5] indicated that a feeling of connectedness with nature is an essential internal driving force that improves ecological behavior. In practice, environmental education imparted in organic surroundings may prove effective in encouraging pro-environmental behavior. Once an individual has established a close sense of unison with the ecological landscape and has profoundly been immersed in an undomesticated environment, protecting Mother Nature becomes a natural extension of sheltering the self [42]. Further, positive environmental behavior may also stem from a person being willing to live a healthy lifestyle and treating oneself with care [45].

However, are all nature-based experiences pleasant? Would those species or ecological phenomena not considered conventionally beautiful and good make one difficult to identify with? Should objects viewed as ugly and deleterious not be protected? Since aesthetic judgment can be highly subjective, it seems to be an unreliable factor in the process of bolstering positive environmental attitudes. After all, objects and events in the natural world are not always viewed as beautiful and good. As a result, the conservation of endangered spiders, snakes, and flies may not be promoted as passionately as 
that of pandas, with their cute appearance (e.g., [46,47]). To more fully make the argument that environmental aesthetics trigger environmental ethics, Rolston reinforced Leopold's discourse with the positive aesthetics that all of nature is beautiful [10]. Positive aesthetics signifies the unconditional recognition of the beauty of nature. All wild and uncivilized entities should be regarded as exquisite. This type of aesthetic judgment, thus, goes beyond mere appearance and transcends the limits of morality as valued by human societies [34].

To ensure positive aesthetics applicable, Rolston [10] advocated an expanded aesthetic view based on environmental knowledge. In this context, scientific cognition may enable us to perceive the beauty of nature in an unprecedented manner. Carlson [34] argued that, just as art history is a necessary foundation for the appreciation of works of art, knowledge of natural history and natural science also plays an indispensable role in the appreciation of nature. In this way, the beauty and ugliness of appearance can be transcended to enable people to experience the beauty of the natural world in-depth [10-13]. For example, some natural phenomena, such as the sight of a moose carcass being eaten by maggots or of lions killing wild deer, may make people uncomfortable. However, with ecological knowledge, they are able to appreciate and are even touched deeply by the vitality of the endless circle of life within ecosystems [10].

The effectiveness of a science-based positive aesthetics remains questionable. In particular, Saito [48] argued that rich ecological knowledge after all is not available to ordinary people. For "aesthetically challenged" species, such as maggots and fleas, the immediate discomfort associated with them make it highly difficult to appreciate their value even with an understanding of the ecosystem. Moreover, rational scientific knowledge may undermine the mystique of nature and result in emotional detachment [44].

\section{Method}

\subsection{Development of Hypothesized Model}

Based on the above discussions, this study assumed that intuitive, emotional engagement and knowledge-based rational cognition toward the environment jointly influence the value judgments and behavioral intentions of an individual. This study integrated the concepts of TRA, TPB, and MREB [22-24]; the notion of Kaiser et al. [2]; and the claims of environmental aestheticians (e.g., [8]) to propose the hypothesized model shown in Figure 2. This model was verified using structural equation modeling (SEM) and collected data.

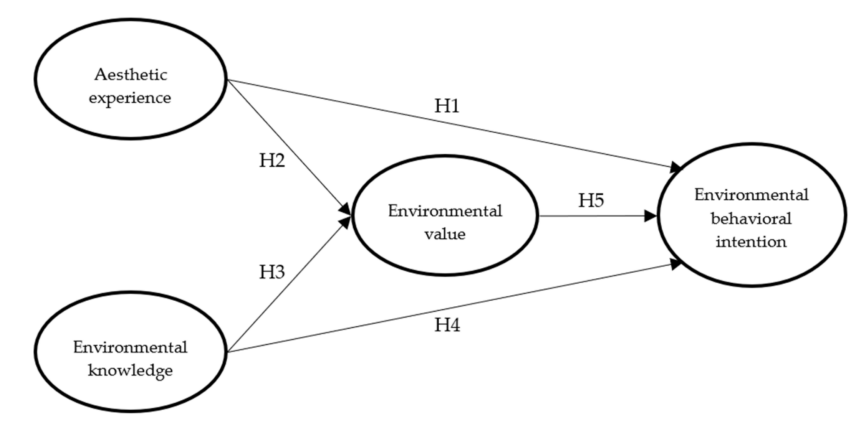

Figure 2. The proposed hypothesized model.

\section{H1: Aesthetic experiences positively affect environmental behavioral intention.}

Related research has indicated that aesthetic experiences are beneficial toward increasing the intention of environmental protection. Generally, people express relatively greater preference for more beautiful species and demonstrate more active, greater intention of their protection. Ecological landscapes that are aesthetically pleasing are more able to elicit the attention of the public, thus encouraging them to participate in their protection. By contrast, for species or landscapes with 
relatively lower aesthetic quality, the public may present lower intentions for their protection (e.g., [46,49,50]).

\section{H2: Aesthetic experiences positively affect environmental value.}

Aesthetic experiences can strengthen people's sense of environmental ethics. Environmental aesthetics contributes to shaping the moral values of an individual. During interactions between humans and the environment, individuals generate aesthetic experiences toward the landscape, enter a process of judgment using their moral values, and then adopt corresponding environmental behavioral intentions [51]. Generally, people tend to protect aesthetically pleasing environments, which generates a sense of pleasing care, because based on their moral values, individuals will regard the protection of beautiful environments as a personal responsibility, rather than a heavy burden [10].

\section{H3: Environmental knowledge positively affects environmental value.}

Environmental value can be defined as the underlying orientations of an individual toward the natural environment (e.g., [52]). Many related studies have indicated that the environmental knowledge of an individual affects the establishment of their environmental awareness, concern, and values (e.g., [3]). Generally, environmental education can increase the knowledge of the public and influence the shaping of individuals' environmental values, thereby increasing their intention toward environmental protection [27].

\section{H4: Environmental knowledge positively affects environmental behavioral intention.}

Kollmuss and Agyeman [3] indicated that, in the models proposed in early studies, environmental education was employed as a means for individuals to acquire knowledge of a certain topic, thereby generating in them specific behavioral intentions and facilitating their engagement in in corresponding behaviors. Related research has indicated that knowledge is a necessary condition that affects individuals' behavioral intention or behavior. Acquiring more environmental knowledge, understanding how to solve environmental issues, or acknowledging the benefits of engaging in environmental protection behavior enhances individuals' intention of environmental protection $[53,54]$.

H5: Environmental value positively affects environmental behavioral intention.

The orientation of an individual's environmental values or beliefs affects their environmental behavioral intention (e.g., $[2,55,56])$. For example, environmental values can predict the behavioral intention of recycling [52] or willingness to select a green hotel [29].

\subsection{Data Collection and Scale Construction}

In this study, questionnaires were employed to collect data, and quantitative analysis was conducted to examine the hypotheses. The participants of this study were students of National Chiayi University located in Southern Taiwan. To ensure that the sample achieved representativeness, students who were taking "general course" were primarily selected as study participants, because all students in Chiayi University are required to acquire credits in general courses to graduate. The questionnaire was officially distributed in classrooms by three course instructors. Students were informed about the purpose of this study, and they were encouraged, but not obligated, to participate in the survey. This survey was conducted in May and June 2017. A total of 275 valid responses were received.

The questionnaire was compiled based on previously-developed related questionnaires (e.g., $[55,57])$ and with reference to the local conditions in Taiwan for revisions. To conform to the logic of Mandarin Chinese and the cultural context of Taiwan, the Mandarin Chinese questionnaire compiled in this study underwent a process of translation and expert review. The final version of the questionnaire for official distribution included items from the Aesthetic Experience Scale (AES) and items related to environmental knowledge, environmental value, and environmental behavioral intention. A five-point Likert scale was employed, with one to five points representing "has never occurred" to "often occurs", or "strongly disagree" to "strongly agree". The questionnaire was also used to collect the demographic data of the participants, including gender, major, economic status, and religious beliefs, to determine the relationship of individual background with aesthetic experience and environmental attitude and intention. 
The scale of aesthetic experience included a total of 28 questions. As an assessment method, a revised version of the AES was used to evaluate the occurrence frequency of individual aesthetic experiences. The content of the scale included reviews of various artistic and non-artistic aesthetic experiences, which corresponded to the study's focus on emotional experience. This scale's design integrated a philosophical and psychological understanding of the aesthetic experience; the scale was divided into five major dimensions that include cognitive synergies and elaboration (integrated cognition of formal and sematic structure), emotional closeness (synesthetic and sympathetic reflection), experiential emotional distancing (association of action and consciousness for the final evaluative and subliminal state), paretelic mode (metamotivational mode and sense of rewarding and pleasing), and expressive perception (assimilation to the dynamic characteristics of objects) [57].

The scale of environmental knowledge, environmental value, and environmental behavior was developed based on the environmental attitude scale established by Kaiser, Wölfing, and Fuhrer [55] and was revised with reference to the local geographical environment and folk customs of Taiwan. The scale included a total of eight questions for environmental knowledge, six for environmental value, and seven for environmental behavioral intention (Table 1).

Table 1. Items for aesthetics experience (AE), environmental knowledge (EK), environmental values $(\mathrm{EV})$, and environmental behavior intention (EBI).

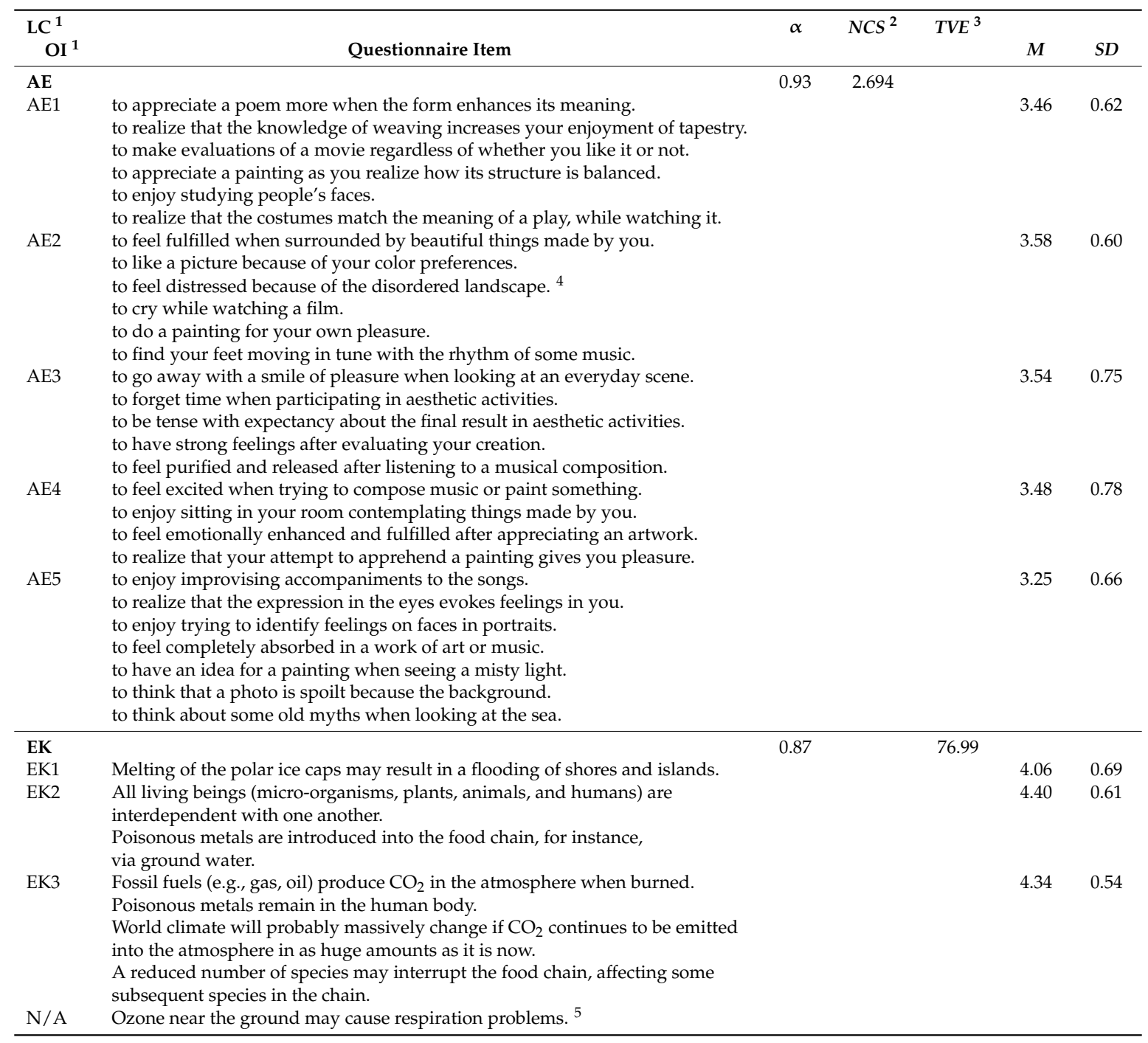


Table 1. Cont.

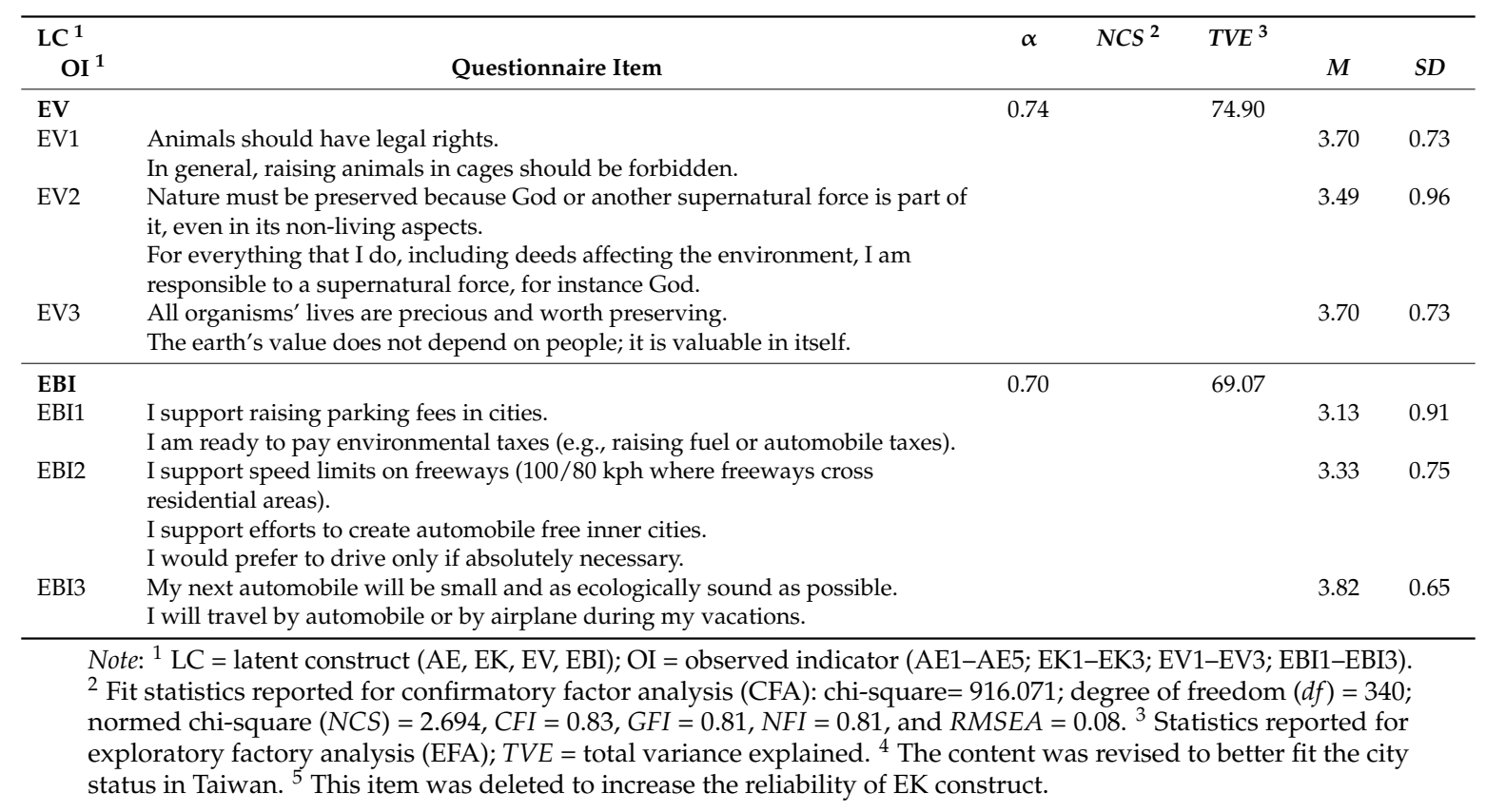

\subsection{Data Processing}

After responses were collected, SPSS 20.0 and AMOS 20.0 were employed to analyze the reliability and validity of the scale (Table 1). The number of items in the questionnaire was compressed based on factor analysis. The factors were treated as observed indicators of latent constructs in the hypothesized model. Based on the principle of parsimony [58], the number of indicators for each latent construct was reduced; as a result, each latent construct had three to five indicators (as the measurement models in SEM) (cf. $[59,60]$ ). Since the AES involved stronger a priori theory and a known factor structure [57], after testing data reliability, confirmatory factor analysis (CFA) was employed to test the suitability of the scale, resulting in five confirmed factors. The goodness-of-fit indices of the measurement model were chi-square $=916.071$, degree of freedom $(\mathrm{DF})=340, \chi^{2} / d f$ (normed chi-square, $\left.\mathrm{NCS}\right)=2.694, \mathrm{CFI}=0.83, \mathrm{GFI}=0.81, \mathrm{NNFI}=0.87$, and RMSEA $=0.08$. The results showed that this measurement model had a favorable goodness of fit (e.g., [61]); thus, the five factors (as observed indicators) of aesthetic experience were used to perform further analyses in SEM. Exploratory factor analyses (EFA) were conducted for items that pertained to environmental knowledge (total variance explained, TVE $=76.99 \%$ ), environmental value $($ TVE $=74.90 \%)$, and environmental behavioral intention (TVE $=69.07 \%)$; the EFAs involved varimax-rotated (orthogonal rotation) principal component analyses, and the results suggested three factors for each latent construct. The Kaiser-Meyer-Olkin (KMO) values for environmental knowledge, environmental value, and environmental behavioral intention were $0.89 \%, 0.72 \%$, and $0.70 \%$, respectively. All Bartlett's tests of sphericity were significant $(p<0.001)$ and suggested the suitability for factor analyses. The value of each indicator of the latent construct was the mean score of the questionnaire items for that factor (Table 1 and Figure 3). 


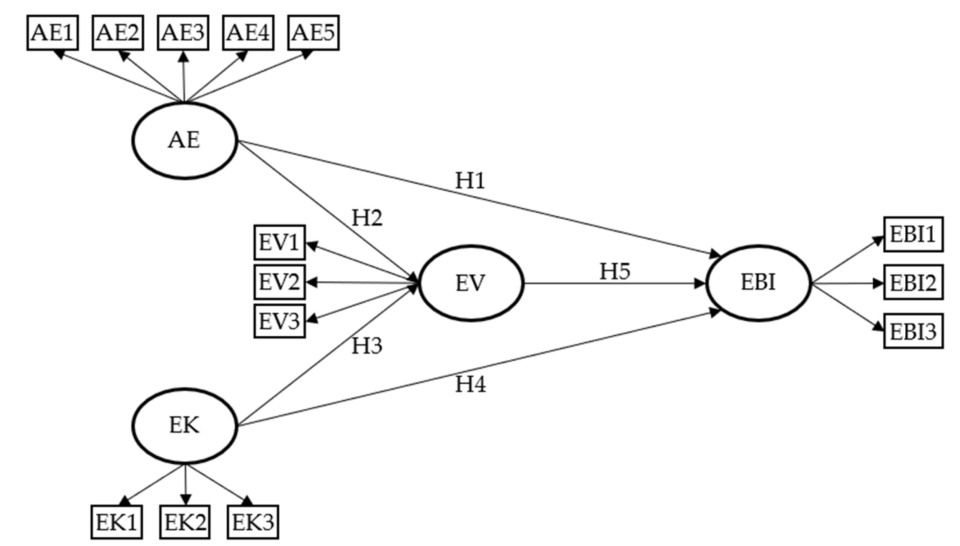

Figure 3. Development of observed indicators for latent constructs in the hypothesized model. Note: Refer to Table 1 for the details of latent constructs (AE, EK, EV, EVI) and observed indicators (AE1-AE5; EK1-EK3; EV1-EV3; EBI1-EBI3).

\section{Results}

\subsection{Participant Demographics}

As shown in Table 2, within the valid sample of this study, the gender ratio between men and women was fairly close (male: 52.7\%; female: 47.3\%). Most participants were aged between 19 and 22 years (92.6\%) and were native-born Taiwanese (97.8\%). The monthly disposable income of students was mostly between 200 and 300 USD (37.3\%). Within the valid sample, more than half of the students were nonreligious $(53.1 \%)$.

Table 2. Descriptive statistics for background variables.

\begin{tabular}{|c|c|c|c|c|c|}
\hline Participant Background & $n^{1}$ & $\%$ & Participant Background (Cont.) & $n^{1}$ & $\%$ \\
\hline Gender & & & Nationality & & \\
\hline Male & 145 & 52.7 & Local student & 269 & 98.9 \\
\hline Female & 130 & 47.3 & Overseas Chinese student & 2 & 0.7 \\
\hline Subtotal & 275 & 100 & Foreign student & 1 & 0.4 \\
\hline Age & & & Subtotal & 272 & 100 \\
\hline$\geq 27$ years & 6 & 2.2 & Monthly disposable income (USD) ${ }^{2}$ & & \\
\hline $23-26$ years & 14 & 5.2 & $<100$ USD & 23 & 9.4 \\
\hline 19-22 years & 252 & 92.6 & 100-200 USD & 54 & 22.1 \\
\hline Subtotal & 272 & 100 & 200-300 USD & 91 & 37.3 \\
\hline Grade & & & 300-400 USD & 41 & 16.8 \\
\hline Freshman & 78 & 28.6 & $>400$ USD & 35 & 14.4 \\
\hline Sophomore & 75 & 27.5 & Subtotal & 244 & 100 \\
\hline Junior & 101 & 37.0 & Religious beliefs & & \\
\hline Senior & 18 & 6.6 & Nonreligious & 146 & 53.1 \\
\hline Other & 1 & 0.3 & Religious & 129 & 46.9 \\
\hline Subtotal & 273 & 100 & Subtotal & 275 & 100 \\
\hline
\end{tabular}

Note: ${ }^{1} n$ is the subsample and the full sample is $N=275$. Due to missing values, the total number of participants for each variable in the table is different and may be less than $275 .{ }^{2}$ The exchange rate of USD to NTD is calculated at 1:30.

\subsection{Reliability and Validity Analysis for Each Latent Construct}

Before testing the structural relationships among latent constructs (measurement models), a reliability and validity analysis was conducted for each construct. As shown in Table 3, the Cronbach's alpha for each latent construct was between 0.70 and 0.93 , and all values were above 0.70 , which suggests that the indicators of each construct had favorable consistency [62]. Moreover, the convergent 
validity of each latent construct was examined with construct reliability (CR) and average variance extracted (AVE) tests. The CR and AVE values for the latent constructs were 0.51-0.91 and 0.26-0.67, respectively. In addition, most values approached or exceeded the desired value [63]. For the discriminant validity test, the AVE square root of each latent construct has to be greater than the value of Pearson correlation coefficient for each construct, which must account for more than $75 \%$ over the overall comparison (e.g., [61]). Hence, all latent constructs in this hypothesized model had a favorable discriminant validity (Table 3).

Table 3. Matrix of reliability, convergent validity, and discriminant validity of constructs.

\begin{tabular}{lccccccc}
\hline Latent Construct & $\alpha$ & $C R$ & $A V E$ & AE & EK & EV & EBI \\
\hline Aesthetic experience (AE) & 0.93 & 0.91 & 0.67 & $0.82^{1}$ & & & \\
Environmental knowledge (EK) & 0.87 & 0.80 & 0.58 & $0.33^{2}$ & $0.76^{1}$ & & \\
Environmental value (EV) & 0.74 & 0.58 & 0.41 & $0.27^{2}$ & $0.29^{2}$ & $0.64^{1}$ & \\
Environmental behavior intention (EBI) & 0.70 & 0.51 & 0.26 & $0.46^{2}$ & $0.52^{2}$ & $0.74^{2}$ & $0.51^{1}$ \\
\hline
\end{tabular}

Note: $\alpha=$ the Cronbach's alpha value for each construct. $C R=$ the composite reliability. $A V E=$ the average variance extracted. ${ }^{1}$ Square root of $A V E .{ }^{2}$ Pearson correlation coefficient between constructs.

\subsection{Analysis of the Structural Model}

The overall results of examination in SEM are shown in Table 4 and Figure 4. To increase the fit statistics of the hypothesized model, the indicator EV1 was deleted due to the undesired factor loading. The goodness-of-fit indices of the structural model were $\chi^{2}=120.41, d f=59, \chi^{2} / d f=2.04, S R M R=0.05$, $R M S E A=0.06, G F I=0.94, A G F I=0.90, N F I=0.92, N N F I=0.94$, and $C F I=0.96$. The results indicated that the model had a favorable goodness of fit [63]. Subsequently, for the path coefficients within the model, the significance of their standardized regression coefficients was separately tested. Table 4 shows that aesthetic experience and environmental knowledge were significantly positive correlated $(\gamma=0.33, t=4.61, p<0.001)$. Furthermore, aesthetic experience exerted significantly positive influences on environmental behavioral intention $(\beta=0.20, t=2.24, p=0.025)$ and environmental value $(\beta=0.20$, $t=2.23, p=0.026)$; similarly, environmental knowledge had a significant effect on environmental value $(\beta=0.22, t=2.08, p=0.037)$ and environmental behavioral intention $(\beta=0.28, t=2.92, p=0.004)$. Additionally, environmental value significantly affected environmental behavioral intention $(\beta=0.60$, $t=3.72, p<0.001)$. From the aforementioned results, all hypotheses in this study were supported.

Of all the path coefficients within this model, environmental behavioral intention was most directly influenced by environmental value, followed by environmental knowledge and aesthetic experience. However, while taking indirect effect into account, although environmental value showed the greatest direct effect $(E V=0.6)$ on environmental behavioral intention, both environmental knowledge and aesthetic experience also had favorable total effects $(\mathrm{EK}=0.41 ; \mathrm{AE}=0.32)$ (Table 4$)$. The results indicate that, in comparison with environmental knowledge, an increase in aesthetic experience can also greatly enhance one's environmental behavioral intention.

Table 4. Path coefficients of the structural model.

\begin{tabular}{lccccccc}
\hline \multicolumn{1}{c}{ Path } & $\begin{array}{c}\text { Standardized } \\
\text { Coefficients }\end{array}$ & $\boldsymbol{t}$-Value & $\boldsymbol{p}$ & Supported & $\begin{array}{c}\text { Direct } \\
\text { Effect }\end{array}$ & $\begin{array}{c}\text { Indirect } \\
\text { Effect }\end{array}$ & $\begin{array}{c}\text { Total } \\
\text { Effect }\end{array}$ \\
\hline $\mathrm{H} 1: \mathrm{AE} \rightarrow \mathrm{EBI}$ & 0.20 & $2.24^{*}$ & 0.025 & Yes & 0.20 & 0.12 & 0.32 \\
$\mathrm{H} 2: \mathrm{AE} \rightarrow \mathrm{EV}$ & 0.20 & $2.23^{*}$ & 0.026 & Yes & 0.20 & - & 0.20 \\
$\mathrm{H} 3: \mathrm{EK} \rightarrow \mathrm{EV}$ & 0.22 & $2.08^{*}$ & 0.037 & Yes & 0.22 & - & 0.22 \\
$\mathrm{H} 4: \mathrm{EK} \rightarrow \mathrm{EBI}$ & 0.28 & $2.92^{* *}$ & 0.004 & Yes & 0.28 & 0.13 & 0.41 \\
$\mathrm{H} 5: \mathrm{EV} \rightarrow \mathrm{EBI}$ & 0.60 & $3.72^{* * *}$ & $<0.001$ & Yes & 0.60 & - & 0.60 \\
$\mathrm{AE} \leftrightarrow \mathrm{EK}$ & 0.33 & $4.61^{* * *}$ & $<0.001$ & Yes & - & - & - \\
\hline
\end{tabular}

Note: $\mathrm{AE}=$ aesthetic experience, $\mathrm{EK}=$ environmental knowledge, $\mathrm{EV}=$ environmental value, and $\mathrm{EBI}=$ Environmental behavior intention. ${ }^{*}, * *$, and ${ }^{* * *}$ denote significance levels at $0.05,0.01$, and 0.001 , respectively. 


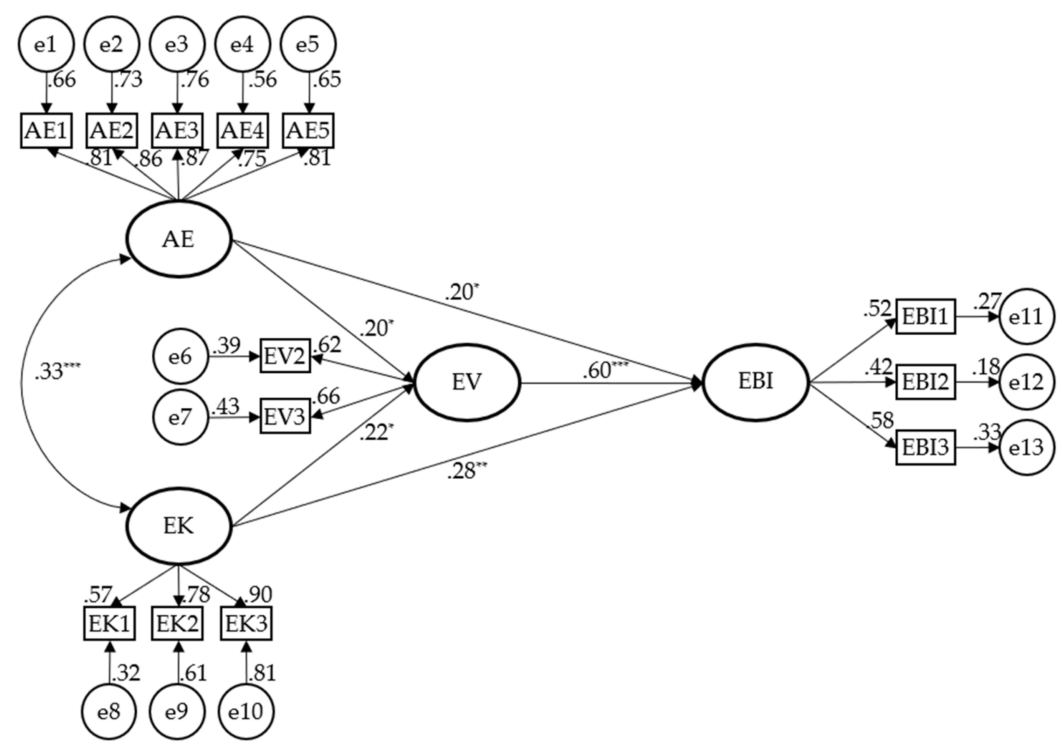

Figure 4. The verification of the hypothesized model with standardized regression coefficients. Note: ${ }^{*} p<0.05,{ }^{* *} p<0.01$, and ${ }^{* *} p<0.001$. Overall model fit: $\chi^{2}=120.41, d f=59, \chi^{2} / d f=2.04, S R M R=0.05$, RMSEA $=0.06, G F I=0.94, A G F I=0.90, N F I=0.92, N N F I=0.94$, and $C F I=0.96$.

\section{Discussion}

\subsection{Environmental Knowledge Emphasized by Traditional Models Was Conducive to Predicting Behavioral Intentions}

The results of this study showed that environmental knowledge played a crucial role in the environmental attitude model, either through directly influencing the environmental behavioral intention of an individual or indirectly influencing environmental behavioral intention through environmental value. Actually, many environmental organizations today operate from the assumption that enhancing environmental knowledge contributes to positive environmental behavior and participation in related environmental strategies or campaigns [3].

This research model verified that environmental knowledge can directly influence the environmental behavioral intention of an individual. This concept echoes that of some models proposed in previous studies (e.g., [2,24]). Environmental knowledge is widely viewed as the basis for encouraging participation in environmental protection activities [54]. Onel and Mukherjee [64] indicated that, when an individual possesses more scientific knowledge or is more familiar with environmental issues, he or she is more willing to pay higher taxes to protect the environment, pay higher prices to purchase environmentally-friendly products, and are even willing to reduce personal living needs.

This research model also verified that environmental knowledge indirectly influences the behavioral intention of an individual through environmental value. In a study on cities in desert regions, Salvaggio et al. [65] found that when individuals were more able to understand the environmental conditions of drought, they were more concerned about the predicament of the water environment, had stronger environmental value orientations, and were more willing to support government policies on water resource protection and price increases on water. Additionally, in a study conducted in China, Fryxell, and Lo [66] indicated that by strengthening environmental knowledge and environmental values, business managers (a group often perceived as being less friendly to the environment) were more willing to fulfill the environmental responsibilities of their firms and strengthen environmental advocacy. A study conducted in Zareie and Navimipour also indicated that enhancing the environmental knowledge and environmental values of college students can directly influence their environmental behavior [67]. 


\subsection{Aesthetic Experience Proved to be an Effective Dimension in the Environmental Attitude Model}

The results of this study showed that the influence of aesthetic experience on environmental value and environmental behavioral intention was similar to that of environmental knowledge. Aesthetic experience can either directly influence the environmental behavioral intention of an individual or indirectly influence the environmental behavioral intention due to environmental values. The findings for both direct and indirect influence are consistent with the beliefs of environmental aestheticians, who maintain that aesthetics is beneficial toward encouraging individuals to engage in environmental protection (e.g., $[6,8,10,44])$. Actually, individuals' feelings toward aesthetic elements in everyday life are often a key factor that determines whether to participate in environmental protection activities such as landscaping and purchasing green products (e.g., $[68,69])$.

Several empirical studies have reported that aesthetic experience has a direct influence on environmental behavioral intention. For example, assessments of the beauty of a species directly influence the degree of support for the conservation of large mammals in Africa (e.g., zebra, buffalo, hyena, and elephant) [70]. Additionally, regarding the indirect influence of aesthetic experience on behavioral intention through environmental value, some empirical studies in Germany have indicated that enhancing individuals' experiences of the natural environment (e.g., aesthetic experiences of plants and animals) is conducive to the establishment of their environmental values, which can then enhance their willingness to protect the environment (e.g., [71]). A study conducted in Australia also confirmed that emotional aesthetic experiences of nature can influence individuals' values and beliefs, which can further influence their intention of environmental protection behavior [72].

\subsection{Complementary Influences and Interaction of Rational Cognition and Emotional Perception}

The environmental aestheticians who maintain the view of positive aesthetics believe that environmental knowledge adds value to the appreciation of the beauty of the environment. The acquisition of environmental knowledge allows individuals to deepen their appreciation of nature from a judgment of aesthetic qualities to respect for the overall ecosystem and the laws of nature [10-13,35]. Comparatively, empirical studies have also shown that intuitive aesthetic experiences can also enhance individuals' interest in learning environmental knowledge and achieve more favorable effects in environmental education (e.g., [71,73]).

Rolston and other environmental aestheticians have tried to ascertain whether aesthetic appreciation should be based on an objective-rational environmental model or a subjective-emotional environmental model (e.g., $[10,15,34,48])$. Interestingly, the results of this study show that the models are closely related. To expand the scope of aesthetic appreciation, emotional environmental perception requires rational environmental knowledge. Otherwise, gaining approval may be more difficult for the ecosystems or species commonly considered to have lower aesthetic quality, such as sludge wetlands of estuaries, spiders, bats, and snakes (e.g., [46,49]). Similarly, rational environmental cognition requires the addition of emotional aesthetic experience. The intuitive experience and emotion often benefits the learning process. For example, researchers focused on the Cerrado region in Brazil, a region rich in natural ecology, and conducted interviews with participants using the method of phenomenology. They found that sensations and feelings induced by local aesthetic experiences strengthened the influences of environmental knowledge in individuals [74].

Leopold's natural writing serves as paramount works demonstrating the merging of rational and emotional environmental perspectives. Although the discussions of Leopold adopt a subjective perspective, they do not rely on the judgments of beauty of individual natural entities; rather, they rely on the objective understanding and appreciation of individual entities and the ecosystem as a whole [75]. Every species has its unique character in its ecosphere that is more fascinating than the aesthetic properties it provides (e.g., the color of a bird's coat or the sound of their call) [8]. In short, the close interaction between rational cognition and emotional perception influence individuals' attitude toward the environment. 


\section{Conclusions}

The emotional and rational model proposed in this study incorporates the dimensions of aesthetic experience into the traditional theory of environmental attitude and behavior. The findings of empirical investigation and analysis show that the overall goodness of fit of the research model is favorable, and that all hypotheses of this study are supported. The purported aesthetic experience is an emotional experience composed of senses, feelings, and imagination. The results indicate that such rich emotional experiences directly enhance the pro-environmental behavioral intention of an individual. This aesthetic experience can also be combined with the rational cognition of individuals toward the environment to jointly induce their identification with environmental value and indirectly enhance their own willingness to protect the environment.

In the proposed model of this research, the cultivation of individuals' aesthetic experiences and their acquisition of environmental knowledge are equally crucial in enhancing their environmental protection intention. In advocating and promoting environmental protection activities, awakening and triggering individuals' ability to emotionally experience the aesthetics of nature is indispensable. Such emotional experience also induces increased attention to environmental ethics and facilitates building a more solid foundation of environmental protection based on people's sincere feelings and respect for the environment. The findings of this study can serve as a reference for environmental management and environmental education practice.

Acknowledgments: We are grateful to the students of the National Chiayi University who participated in this study. We also appreciate Chin-Fah Wang, Su-Chong Chuang, and Angel Hsi-I Chen who helped to distribute the questionnaires in their general courses. We are thankful for the research assistant Yuan-Tai Chen for his thoughtful help. Furthermore, we would like to thank the anonymous reviewers for their insightful and constructive comments to improve the quality of the paper.

Author Contributions: Po-Ching Wang and Chi-Ying Yu conceived the study. Po-Ching Wang designed the research method. Po-Ching Wang coordinated the data collection and data processing procedure. Po-Ching Wang and Chi-Ying Yu discussed the results and contributed to the final manuscript.

Conflicts of Interest: The authors declare no conflict of interest.

\section{References}

1. Allport, G.W. Attitudes. In Handbook of Social Psychology; Murchison, C., Ed.; Clark University Press: Worcester, MA, USA, 1935; pp. 798-844.

2. Kaiser, F.G.; Ranney, M.; Hartig, T.; Bowler, P.A. Ecological behavior, environmental attitude, and feelings of responsibility for the environment. Eur. Psychol. 1999, 4, 59. [CrossRef]

3. Kollmuss, A.; Agyeman, J. Mind the gap: Why do people act environmentally and what are the barriers to pro-environmental behavior? Environ. Educ. Res. 2002, 8, 239-260. [CrossRef]

4. Ramsey, C.E.; Rickson, R.E. Environmental knowledge and attitudes. J. Environ. Educ. 1976, 8, 10-18. [CrossRef]

5. Otto, S.; Pensini, P. Nature-based environmental education of children: Environmental knowledge and connectedness to nature, together, are related to ecological behavior. Global Environ. Chang. 2017, 47, 88-94. [CrossRef]

6. Hargrove, E.C. Foundations of Environmental Ethics; Prentice-Hall: Englewood Cliffs, NJ, USA, 1989.

7. Callicott, J.B. Companion to a Sand County Almanac: Interpretive \& Critical Essays; University of Wisconsin Press: Madison, WI, USA, 1987.

8. Callicott, J.B. In Defense of the Land Ethic: Essays in Environmental Philosophy, Albany; State University of New York Press: New York, NY, USA, 1989.

9. Leopold, A. A Sand County Almanc and Sketches Here and There; Oxford University Press: New York, NY, USA, 1949.

10. Rolston III, H. From beauty to duty: Aesthetics of nature and environmental ethics. In Environment and the Arts: Perspectives on Environmental Aesthetics; Berleant, A., Ed.; Ashgate: Burlington, VT, USA, 2002; pp. 127-141. 
11. Rolston III, H. Environmental Ethics: Duties to and Values in the Natural World; Temple University Press: Philadelphia, PA, USA, 1988.

12. Rolston III, H. Disvalues in nature. Monist 1992, 75, 250-278. [CrossRef]

13. Rolston III, H. Aesthetic experience in forests. J. Aesthet. Art Crit. 1998, 56, 157-166. [CrossRef]

14. Vanstockem, J.; Vranken, L.; Bleys, B.; Somers, B.; Hermy, M. Do Looks Matter? A Case Study on Extensive Green Roofs Using Discrete Choice Experiments. Sustainability 2018, 10, 309. [CrossRef]

15. Kim, S.; An, K. Exploring Psychological and Aesthetic Approaches of Bio-Retention Facilities in the Urban Open Space. Sustainability 2017, 9, 2067. [CrossRef]

16. Carroll, N. On being moved by nature: Between religion and natural history. In Landscape, Natural Beauty and the Arts; Kemal, S., Gaskell, I., Eds.; Cambridge University Press: Cambridge, UK, 1995; pp. 244-266.

17. Bettinghaus, E.P. Health promotion and the knowledge-attitude-behavior continuum. Prev. Med. 1986, 15, 475-491. [CrossRef]

18. Schwartz, N.E. The Relationship of Nutrition Education to Subsequent Knowledge, Attitudes, and Practices of Ohio High School Graduates. Ph.D. Thesis, The Ohio State University, Columbus, OH, USA, 1973.

19. Smith, M.B. The personal setting of public opinions: A study of attitudes toward Russia. Public Opin. Q. 1947, 11, 507-523. [CrossRef]

20. Breckler, S.J. Empirical validation of affect, behavior, and cognition as distinct components of attitude. J. Pers. Soc. Psychol. 1984, 47, 1191. [CrossRef] [PubMed]

21. Grob, A. A structural model of environmental attitudes and behaviour. J. Environ. Psychol. 1995, 15, $209-220$. [CrossRef]

22. Fishbein, M.; Ajzen, I. Belief, Attitude, Intention and Behavior: An Introduction to Theory and Research; Addison-Wesley: Reading, MA, USA, 1975.

23. Ajzen, I. From intentions to actions: A theory of planned behavior. In Action-control: From Cognitions to Behavior; Kuhland, J., Beckman, J., Eds.; Springer: Heidelberg, Germany, 1985; pp. 11-39.

24. Hines, J.M.; Hungerford, H.R.; Tomera, A.N. Analysis and synthesis of research on responsible environmental behavior: A meta-analysis. J. Environ. Educ. 1987, 18, 1-8. [CrossRef]

25. Stern, P.C.; Dietz, T.; Abel, T.; Guagnano, G.A.; Kalof, L. A value-belief-norm theory of support for social movements: The case of environmentalism. Hum. Ecol. Rev. 1999, 6, 81.

26. Schwartz, S.H. Normative influences on altruism. Adv. Exp. Soc. Psychol. 1977, 10, 221-279.

27. Bang, H.K.; Ellinger, A.E.; Hadjimarcou, J.; Traichal, P.A. Consumer concern, knowledge, belief, and attitude toward renewable energy: An application of the reasoned action theory. Psychol. Market. 2000, 17, 449-468. [CrossRef]

28. Cordano, M.; Frieze, I.H. Pollution reduction preferences of US environmental managers: Applying Ajzen's theory of planned behavior. Acad. Manag. J. 2000, 43, 627-641. [CrossRef]

29. Han, H.; Hsu, L.T.J.; Sheu, C. Application of the theory of planned behavior to green hotel choice: Testing the effect of environmental friendly activities. Tour. Manag. 2010, 31, 325-334. [CrossRef]

30. Oreg, S.; Katz-Gerro, T. Predicting proenvironmental behavior cross-nationally: Values, the theory of planned behavior, and value-belief-norm theory. Environ. Behav. 2006, 38, 462-483. [CrossRef]

31. Hammermeister, K. The German Aesthetic Tradition; Cambridge University Press: Cambridge, UK, 2002.

32. Kant, I. Critique of Judgment; Pluhar, W.S., Translator; Hackett Publishing Co.: Indianapolis, IN, USA; Cambridge, UK, 1987. (Original work published 1790).

33. Burke, E. A Philosophical Enquiry into the Origin of Our Ideas of the Sublime and Beautiful; Oxford University Press: Oxford, UK, 1757.

34. Carlson, A. Nature and Landscape: An Introduction to Environmental Aesthetics; Columbia University Press: New York, NY, USA, 2009.

35. Hepburn, R. Contemporary aesthetics and the neglect of natural beauty. In The Aesthetics of Natural Environments; Carlson, A., Berleant, A., Eds.; Broadview Press: Peterborough, ON, Canada, 2004; pp. 44-62.

36. Hepburn, R. 'Being' as a concept of aesthetics. Br. J. Aesthet. 1968, 8, 138-146. [CrossRef]

37. Godlovitch, S. Offending against nature. Environ. Values 1998, 7, 131-150. [CrossRef]

38. Hepburn, R. Landscape and the metaphysical imagination. In The Aesthetics of Natural Environments; Carlson, A., Berleant, A., Eds.; Broadview Press: Peterborough, ON, Canada, 2004; pp. 127-140.

39. Lu, D.; Liu, Y.; Lai, I.; Yang, L. Awe: An Important Emotional Experience in Sustainable Tourism. Sustainability 2017, 9, 2189. [CrossRef] 
40. de Lacy, P.; Shackleton, C. Aesthetic and Spiritual Ecosystem Services Provided by Urban Sacred Sites. Sustainability 2017, 9, 1628. [CrossRef]

41. Schultz, P.W.; Shriver, C.; Tabanico, J.J.; Khazian, A.M. Implicit connections with nature. J. Environ. Psychol. 2004, 24, 31-42. [CrossRef]

42. Mayer, F.S.; Frantz, C.M. The connectedness to nature scale: A measure of individuals' feeling in community with nature. J. Environ. Psychol. 2004, 24, 503-515. [CrossRef]

43. Perrin, J.L.; Benassi, V.A. The connectedness to nature scale: A measure of emotional connection to nature? J. Environ. Psychol. 2009, 29, 434-440. [CrossRef]

44. Brady, E. Imagination and the aesthetic appreciation of nature. J. Aesthet. Art Crit. 1998, 56, $139-147$. [CrossRef]

45. Geiger, S.M.; Otto, S.; Schrader, U. Mindfully green and healthy: An indirect path from mindfulness to ecological behavior. Front. Psychol. 2017, 8, 02306. [CrossRef] [PubMed]

46. Knight, A.J. "Bats, snakes and spiders, Oh my!" How aesthetic and negativistic attitudes, and other concepts predict support for species protection. J. Environ. Psychol. 2008, 28, 94-103. [CrossRef]

47. Kane, A.; Wolter, K.; Neser, W.; Kotze, A.; Naidoo, V.; Monadjem, A. Home range and habitat selection of Cape Vultures Gyps coprotheres in relation to supplementary feeding. Bird Study 2016, 63, 387-394. [CrossRef]

48. Saito, Y. The aesthetics of unscenic nature. J. Aesthet. Art Crit. 1998, 56, 101-111. [CrossRef]

49. Lee, L.-H. Perspectives on landscape aesthetics for the ecological conservation of wetlands. Wetlands 2017, 37, 381-389. [CrossRef]

50. Manesi, Z.; Van Lange, P.A.; Pollet, T.V. Butterfly eyespots: Their potential influence on aesthetic preferences and conservation attitudes. PLoS ONE 2015, 10, e0141433. [CrossRef] [PubMed]

51. Gobster, P.H.; Nassauer, J.I.; Daniel, T.C.; Fry, G. The shared landscape: What does aesthetics have to do with ecology? Landsc. Ecol. 2007, 22, 959-972. [CrossRef]

52. Barr, S. Factors influencing environmental attitudes and behaviors: A UK case study of household waste management. Environ. Behav. 2007, 39, 435-473. [CrossRef]

53. Frick, J.; Kaiser, F.G.; Wilson, M. Environmental knowledge and conservation behavior: Exploring prevalence and structure in a representative sample. Pers. Individ. Dif. 2004, 37, 1597-1613. [CrossRef]

54. Gifford, R.; Nilsson, A. Personal and social factors that influence pro-environmental concern and behaviour: A review. Int. J. Psychol. 2014, 49, 141-157. [CrossRef] [PubMed]

55. Kaiser, F.G.; Wölfing, S.; Fuhrer, U. Environmental attitude and ecological behaviour. J. Environ. Psychol. 1999, 19, 1-19. [CrossRef]

56. Raymond, C.M.; Brown, G.; Robinson, G.M. The influence of place attachment, and moral and normative concerns on the conservation of native vegetation: A test of two behavioural models. J. Environ. Psychol. 2011, 31, 323-335. [CrossRef]

57. Stamatopoulou, D. Integrating the philosophy and psychology of aesthetic experience: Development of the Aesthetic Experience Scale. Psychol. Rep. 2004, 95, 673-695. [CrossRef] [PubMed]

58. Popper, K.R. The Logic of Scientific Discovery; Harper \& Row: New York, NY, USA, 1959.

59. Boomsma, A.; Hoogland, J.J. The robustness of LISREL modeling revisited. Structural equation models: Present and future. A Festschrift in Honor of Karl Jöreskog 2001, 2, 139-168.

60. Iacobucci, D. Structural equations modeling: Fit indices, sample size, and advanced topics. J. Consum. Psychol. 2010, 20, 90-98. [CrossRef]

61. Hair, J.F.; Black, B.; Babin, B.; Anderson, R.E. Multivariate Data Analysis, 7th ed.; Prentice Hall: Upper Saddle River, NJ, USA, 2010.

62. Gliem, J.; Gliem, R. Calculating, Interpreting, and Reporting Cronbach's Alpha Reliability Coefficient for Likert-Type Scales. In Proceedings of the 2003 Midwest Research to Practice Conference in Adult, Continuing and Community Education, The Ohio State University, Columbus, OH, USA, 8-10 October 2003.

63. Bagozzi, R.P.; Yi, Y. Specification, evaluation, and interpretation of structural equation models. J. Acad. Mark. Sci. 2012, 40, 8-34. [CrossRef]

64. Onel, N.; Mukherjee, A. Consumer knowledge in pro-environmental behavior: An exploration of its antecedents and consequences. World J. Sci. Technol. Sustain. Dev. 2016, 13, 328-352. [CrossRef] 
65. Salvaggio, M.; Futrell, R.; Batson, C.D.; Brents, B.G. Water scarcity in the desert metropolis: How environmental values, knowledge and concern affect Las Vegas residents' support for water conservation policy. J. Environ. Plann. Manag. 2014, 57, 588-611. [CrossRef]

66. Fryxell, G.E.; Lo, C.W. The influence of environmental knowledge and values on managerial behaviours on behalf of the environment: An empirical examination of managers in China. J. Bus. Ethics 2003, 46, 45-69. [CrossRef]

67. Zareie, B.; Navimipour, N.J. The impact of electronic environmental knowledge on the environmental behaviors of people. Comput. Hum. Behav. 2016, 59, 1-8. [CrossRef]

68. Bagozzi, R.P.; Dabholkar, P.A. Consumer recycling goals and their effect on decisions to recycle: A means-end chain analysis. Psychol. Market. 1994, 11, 313-340. [CrossRef]

69. Todd, A.M. The aesthetic turn in green marketing: Environmental consumer ethics of natural personal care products. Ethics Environ. 2004, 9, 86-102. [CrossRef]

70. de Pinho, J.R.; Grilo, C.; Boone, R.B.; Galvin, K.A.; Snodgrass, J.G. Influence of aesthetic appreciation of wildlife species on attitudes towards their conservation in Kenyan agropastoralist communities. PLoS ONE 2014, 9, e88842. [CrossRef] [PubMed]

71. Bögeholz, S. Nature experience and its importance for environmental knowledge, values and action: Recent German empirical contributions. Environ. Educ. Res. 2006, 12, 65-84. [CrossRef]

72. Ford, R.M.; Williams, K.J.; Smith, E.L.; Bishop, I.D. Beauty, belief, and trust: Toward a model of psychological processes in public acceptance of forest management. Environ. Behav. 2014, 46, 476-506. [CrossRef]

73. Farmer, J.; Knapp, D.; Benton, G.M. An elementary school environmental education field trip: Long-term effects on ecological and environmental knowledge and attitude development. J. Environ. Educ. 2007, 38, 33-42. [CrossRef]

74. Iared, V.G.; de Oliveira, H.T.; Reid, A. Aesthetic experiences in the Cerrado (Brazilian savanna): Contributions to environmental education practice and research. Environ. Educ. Res. 2017, 23, 1273-1290. [CrossRef]

75. Fudge, R.S. Imagination and the science-based aesthetic appreciation of unscenic nature. J. Aesthet. Art Crit. 2001, 59, 275. [CrossRef] 